\title{
Adaptation of Fusarium graminearum to Tebuconazole Yielded Descendants Diverging for Levels of Fitness, Fungicide Resistance, Virulence, and Mycotoxin Production
}

\author{
Rayko Becher, Ursula Hettwer, Petr Karlovsky, Holger B. Deising, and Stefan G. R. Wirsel
}

First, fourth, and fifth authors: Martin-Luther-Universität Halle-Wittenberg, Institut für Agrar- und Ernährungswissenschaften, BettyHeimann-Str. 3, D-06120 Halle (Saale), Germany; and second and third authors: Georg-August-Universität Göttingen, Molecular Phytopathology and Mycotoxin Research Section, Grisebachstr. 6, D-37077 Göttingen, Germany. Accepted for publication 26 December 2009.

\begin{abstract}
Becher, R., Hettwer, U., Karlovsky, P., Deising, H. B., and Wirsel, S. G. R. 2010. Adaptation of Fusarium graminearum to tebuconazole yielded descendants diverging for levels of fitness, fungicide resistance, virulence, and mycotoxin production. Phytopathology 100:444-453.

Azole fungicides play a prominent role for reliable plant disease management. However, quantitative azole resistance has been shown to develop in fungal pathogens, including Fusarium graminearum, the causal agent of Fusarium head blight (FHB). Due to widespread application of azole fungicides, resistance may accumulate to higher degrees in fungal field populations over time. Although azole fungicides

Two morphologically distinguishable azole-resistant phenotypes were recovered that differed with regard to levels of fitness, fungicide resistance, virulence, and mycotoxin production. Isolates of the adapted "phenotype 1" exhibited azole-specific cross-resistance, whereas "phenotype 2" isolates displayed the phenomenon of multidrug resistance because the sensitivity to amine fungicides was also affected. Assessment of individual infected spikelets for mycotoxin contents by high-performance liquid chromatography mass spectrometry and for Fusarium DNA by quantitative polymerase chain reaction indicated that some of the adapted isolates produced significantly higher levels of nivalenol per fungal biomass than the NRRL 13383 strain.
\end{abstract} are prominent components in FHB control, little effort has been made to investigate azole resistance in $F$. graminearum. We allowed $F$. graminearum strain NRRL 13383 to adapt to an azole fungicide in vitro, applying a strongly growth-reducing but sublethal dose of tebuconazole.
Additional keywords: DMIs, fenpropimorph, Gibberella zeae, prochloraz, prothioconazole, spiroxamine, trichothecene, zearalenone.
The ascomycete Fusarium graminearum Schwabe (teleomorph Gibberella zeae (Schwein.) Petch) is a major causal agent of Fusarium head blight (FHB), a destructive floral disease of small grain cereals strongly compromising wheat production in many parts of the world (23). Infection primarily leads to the reduction of yield and quality of the harvested grain and secondarily to seedling blight when infected grains are used for sowing (41). Importantly, $F$. graminearum produces several potent mycotoxins that have detrimental impact on human and animal health $(43,53)$. The most prominent mycotoxins are the trichothecenes deoxynivalenol (DON) and nivalenol (NIV) and the estrogenic polyketide zearalenone (ZEA). Severe outbreaks of human and animal toxicoses in history could be traced back to toxication with Fusarium mycotoxins (14). As food safety and consumer protection have gained considerable attention, strict regulations for tolerated levels of Fusarium mycotoxins in cereals and products derived thereof have been established (21).

The increase in FHB prevalence and severity during the last decades in many wheat-growing regions of the world has stimulated research on disease mechanisms and control. Although crop rotation, tillage practices, and breeding for FHB resistance have made considerable progress in wheat, fungicide application is an indispensable measure to limit FHB severity and mycotoxin contaminations $(3,20,36)$. Several studies have shown that appli-

Corresponding author: S. G. R. Wirsel;

E-mail address: stefan.wirsel@landw.uni-halle.de

doi:10.1094/PHYTO-100-5-0444

(C) 2010 The American Phytopathological Society cation of some azole fungicides (e.g., tebuconazole) at anthesis can consistently control the disease.

Azole fungicides are one of the most important classes of systemic site-specific fungicides that have been intensively used since the 1980s against a broad spectrum of plant-pathogenic fungi. They inhibit the cytochrome P450 sterol $14 \alpha$-demethylase (CYP51), an enzyme that is essential for ergosterol biosynthesis, leading to disturbance of fungal membrane integrity (8). Together with piperazine, pyridine, and pyrimidine fungicides that act at the same target site, the azoles are grouped as demethylation inhibitors (DMIs) (30). In contrast to other site-specific fungicides that were rendered ineffective due to point mutations at the genes encoding the target proteins, the efficacy of DMIs has decreased relatively slowly and gradually (7). Dose-response curves observed with single-spore isolates of fungal field populations exhibited the presence of a continuum of levels of DMI resistance (16), indicating that quantitative fungicide resistance had developed. Several studies have shown that decreased azole sensitivity is due to different mechanisms, such as (i) target-site alterations based on point mutations in the CYP51 gene $(31,51)$, (ii) overexpression of the target gene $(24,44)$, (iii) alterations in sterol biosynthesis and cellular sterol composition $(25,26)$, (iv) enhanced energy-dependent efflux transport of the toxic compound $(38,42)$, and (v) increased copy numbers of the target gene and a transcriptional regulator of drug efflux pumps (46). Additive effects were also reported among these mechanisms $(28,46,49)$. Strains with reduced sensitivity were found in field populations of, for example, Blumeria graminis f. sp. tritici (22), Botrytis cinerea (48), and Mycosphaerella graminicola (35), partially compromising an effective disease control. The fact that azoles 
are the most prominent fungicide class used in cereals today raised significant concerns about the development and accumulation of azole resistance.

Fungicide resistance can be studied by analyzing parameters such as resistance and cross-resistance levels, or mycotoxin chemotype of isolates from fields that have a known history of fungicide treatment. However, field isolates often have an undefined genetic background, which makes it difficult to compare them directly to a reference genotype, for example, by analyzing expression levels of putatively affected genes by quantitative reverse-transcription polymerase chain reaction (qRT-PCR) experiments. This limitation can be overcome by using a characterized reference strain for selecting fungicide-resistant descendants in vitro under controlled experimental conditions. This can be achieved by several methods such as short exposures to UV light or chemical mutagens to introduce mutations. Other methods aim at selecting existing mutations, which can be accomplished by treating large numbers of spores with a fungicide. Alternatively, spontaneous genetic alterations can be selected by continuous exposure of fungal mycelia to a sublethal fungicide concentration, which is referred to as adaptation. The latter approach has been successfully used in previous studies $(12,47,49)$. Reasons for the observed adaptability in the absence of mutagens were discussed (10). Due to the smaller scale of in vitro experiments compared with the selection occurring in the field, such experiments may only uncover some part of the genetic alterations leading to fungicide resistance; however, genetic alterations identified in mycelia continuously exposed to fungicides may be relevant in agronomical settings.

In spite of its agroeconomic importance, little is currently known about azole resistance in $F$. graminearum. A small-scale study on strains isolated from German fields during 1987 to 2004 suggested declining triazole sensitivity (29). Another report described three DMI-resistant isolates that were discovered among 159 field isolates from China (52). In order to study the development of azole resistance in $F$. graminearum, we selected isolates in vitro and under controlled conditions that exhibited reduced levels of sensitivity for tebuconazole. Adapted strains were evaluated for the level of fungicide resistance acquired, general vitality, and virulence. To assess the in planta mycotoxin production per fungal biomass, we took advantage of methods that allowed us to resolve mycotoxin production and DNA quantification at the level of individual spikelets.

\section{MATERIALS AND METHODS}

Cultivation and storage of fungi. The $F$. graminearum reference strain NRRL 13383 (kindly provided by Kerry O'Donnell, National Center for Agricultural Utilization Research, United States Department of Agriculture-Agricultural Research Service, Peoria, II), which was originally isolated from corn in Iran, was used as the parental isolate for adaptation. Within the F. graminearum species complex, it belongs to lineage 7 (39) that was referred to as $F$. graminearum sensu stricto (40). NRRL 13383 was identified as a strong NIV producer that is highly aggressive to wheat (23). The nonadapted reference strain as well as the adapted isolates generated in this study were stored as conidial suspensions $\left(10^{6}\right.$ conidia $\left./ \mathrm{ml}\right)$ in $20 \%$ (vol $/ \mathrm{vol}$ ) glycerol at $-70^{\circ} \mathrm{C}$. For subsequent cultivation, $20 \mu \mathrm{l}$ of the freezer stock was transferred to a potato dextrose agar (PDA) (Becton Dickinson $\mathrm{GmbH}$, Heidelberg, Germany) plate and incubated for 5 days at $23^{\circ} \mathrm{C}$ in darkness.

Determination of parameters of fungal fitness. Growth rates of nonadapted and adapted isolates were determined at different temperatures $\left(7,15,23\right.$, and $\left.30^{\circ} \mathrm{C}\right)$. Mycelial plugs $(5 \mathrm{~mm}$ in diameter) were excised from the margins of 5-day-old colonies and placed upside down in the centers of PDA plates $(90 \mathrm{~mm}$ in diameter). Growth of the colonies was linear between days 2 and
6 , and mycelial growth was measured on the fourth and fifth day in two perpendicular directions. Three replicates were analyzed per isolate and temperature. Averaged colony diameters were used to calculate radial growth.

Conidia were produced in 300-ml flasks filled with $50 \mathrm{ml}$ of mung bean broth (MBB) (4) that was inoculated with five colonized PDA plugs and incubated for 7 days at ambient light and temperature conditions, with shaking $(50 \mathrm{rpm})$. To assess the in vitro sporulation capacity of isolates, spore concentrations were determined using a hematocytometer and five biological repeats. If needed for further experimentation, spores were collected by filtering the broth through Miracloth (Merck KGaA, Darmstadt, Germany) into a 50-ml tube with centrifugation for $10 \mathrm{~min}$ at $3,000 \times g$. After transfer to a 2-ml tube, spores were washed twice with and finally suspended in $1 \mathrm{ml}$ of sterile $0.01 \%$ ( $\mathrm{vol} / \mathrm{vol}$ ) Tween 20.

To assess the conidial germination rate, $20 \mu \mathrm{l}$ of a suspension with $5 \times 10^{4}$ conidia/ml was placed on coverslips and incubated in a glass petri dish at $100 \%$ relative humidity (r.h.). After $24 \mathrm{~h}$, germination rates were determined by bright-field microscopy (Nikon Eclipse E600; Nikon GmbH, Düsseldorf, Germany). For each strain, the germination rate was assessed in three biological repeats of 200 conidia.

Adaptation procedure. The triazole tebuconazole (FOLICUR; Bayer CropScience, Monheim, Germany) was used for adaptation. The $F$. graminearum strain NRRL 13383 was grown as a submerged culture in liquid media to ensure that the fungicide permeated the entire mycelium. A 300-ml flask containing $100 \mathrm{ml}$ of potato dextrose broth (PDB) was inoculated with three mycelial plugs $(5 \mathrm{~mm}$ in diameter) and incubated with shaking at $100 \mathrm{rpm}$ in darkness at $23^{\circ} \mathrm{C}$. Two days later, tebuconazole was added to PDB to result in a concentration of $10 \mathrm{mg} / \mathrm{liter}$. Incubation continued for another 33 days with two exchanges of the spent medium with fresh fungicide-amended medium after the 11th and 22nd day. This adaptation procedure was performed in four biological repeats. The mycelia were harvested by filtration through sterile filter papers and then suspended in twice of their estimated volumes of $20 \%$ ( $\mathrm{vol} / \mathrm{vol}$ ) glycerol. Subsequently, the mycelial suspensions were blended (Ultra Turrax; IKA Labortechnik, Staufen, Germany) for $30 \mathrm{~s}$ using speed 5 and stored at $-70^{\circ} \mathrm{C}$.

To obtain strains that originated from single spores, $100 \mu \mathrm{l}$ of the freezer stock was used for inoculation of MBB to induce conidiation as described above. Thus, a suspension of conidia was produced that was serially diluted and spread onto PDA amended with tebuconazole at $10 \mathrm{mg} / \mathrm{liter}$. Agar plugs from single colonies were transferred to PDB and MBB to produce mycelial (first generation after adaptation) and conidial suspensions (second generation), respectively, of the resistant strains that were kept as glycerol stocks as described above.

To test for mitotic stability of acquired resistance, isolates underwent further sub-cultivation. The conidial freezer stocks (20 $\mu \mathrm{l}$, second generation) were transferred to PDA and incubated for 5 days at $23^{\circ} \mathrm{C}$ in darkness. Subsequently, MBB was inoculated and incubated as above. After 7 days, $10 \mu \mathrm{l}$ of a conidial suspension was transferred to PDA and the subcultivation procedure was correspondingly repeated until the sixth conidial generation.

Assessment of fungicide sensitivity. Sensitivity to tebuconazole was quantified by measuring radial growth of NRRL 13383 and the derived adapted isolates on PDA adjusted to different tebuconazole concentrations $(0,0.025,0.05,0.075,0.1,0.5,1.0$, 2.5, 5.0, 10.0, and $30.0 \mathrm{mg} /$ liter) in three replicates each. After 6 days of incubation at $23^{\circ} \mathrm{C}$ in darkness, colony diameters were measured in two perpendicular directions and the original plug diameter was subtracted. Furthermore, the inhibitory effect of the fungicide on conidial germination was assayed. In all, $\approx 1,000$ spores in $20 \mu \mathrm{l}$ of PDB amended with tebuconazole $(0,0.5,1.0$, $2.0,3.0,4.0,5.0,7.5$, or $10.0 \mathrm{mg} /$ liter) were placed on coverslips, 
transferred to glass petri dishes, and incubated for $24 \mathrm{~h}$ at $100 \%$ r.h. and $23^{\circ} \mathrm{C}$ in darkness. For each strain and each concentration, germination was assessed by bright-field microscopy in three repeats. Because azole fungicides may not directly affect spore germination due to endogenous sterol reserves, spores were counted as germinated only when the length of the germ tube was at least twice the spore length. Effective inhibition of mycelial growth and conidial germination were determined for each fungicide concentration relative to control medium without fungicides. Effective doses leading to a 50 or $90 \%$ inhibition $\left(\mathrm{ED}_{50}\right.$ and $\mathrm{ED}_{90}$, respectively) were calculated on the basis of a linear regression analysis of logit-transformed fungicide efficiency and the $\log _{10}$ transformed fungicide concentrations as described (42). These sensitivity assays were not only performed for the second vegetative generation after adaptation but also for mycelia and conidia of the sixth generation.

In addition, a qualitative cross-resistance assay was conducted with prothioconazole (PROLINE) and spiroxamine (PROSPER) (Bayer CropScience $\mathrm{GmbH}$ ) as well as prochloraz (SPORTAK 45 EW) and fenpropimorph (CORBEL) (BASF SE, Ludwigshafen, Germany). In a preliminary screen for fungal growth on various concentrations of these fungicides, discriminatory doses were determined at which the parental isolate showed no or very little growth. For comparison of the isolates, $2 \mu \mathrm{l}$ of $10^{6}$ conidia/ml was applied onto PDA amended with prothioconazole at $15 \mathrm{mg} / \mathrm{liter}$, prochloraz at $0.15 \mathrm{mg} / \mathrm{liter}$, spiroxamine at $285 \mathrm{mg} / \mathrm{liter}$, or fenpropimorph at $100 \mathrm{mg} /$ liter and incubated at $23^{\circ} \mathrm{C}$ in darkness. After 7 days, plates were photographed (Nikon D50; Nikon $\mathrm{GmbH})$.

Plant infection assay. Virulence of nonadapted and adapted $F$. graminearum isolates was tested as previously described (23), with minor modifications. Briefly, FHB-susceptible spring wheat cv. Picolo (Saatzucht Dr. J. Ackermann \& Co., Irlbach, Germany) was grown until anthesis in the greenhouse at $26 \pm 4{ }^{\circ} \mathrm{C}$ with $16 \mathrm{~h}$ of supplemental light. Three seeds were planted per $14-\mathrm{cm}$ pot containing steamed garden soil. The pots were watered daily, their positions were exchanged randomly once a week, and they were fertilized 28 days after planting by the addition of $4 \mathrm{~g}$ of mineral fertilizer Plantosan Compact (NPK[Mg], 15-8-15-[2]) (SpiessUrania Chemicals $\mathrm{GmbH}$, Hamburg, Germany). At anthesis, $10 \mu \mathrm{l}$ of a suspension containing $1 \times 10^{6}$ spores $/ \mathrm{ml}$ (in $0.01 \%$ Tween 20) was applied into the ninth spikelet. For assaying infection in the presence of fungicide, conidial suspensions were adjusted to contain a tebuconazole concentration of $10 \mathrm{mg} /$ liter immediately before inoculation. After inoculation, each head was sprayed with $0.5 \mathrm{ml}$ of sterile water and individually enclosed in a moistened plastic bag for $72 \mathrm{~h}$. The inoculated plants were incubated in a controlled growth chamber (Percival Scientific AR-75HIL; Percival Scientific Inc., Perry, IA) that was kept at $27^{\circ} \mathrm{C}, 75 \%$ r.h. and a 16-h photoperiod applying a light intensity of $200 \mu \mathrm{E} \mathrm{m}^{-2} \mathrm{~s}^{-1}$ at soil level. Fourteen days postinoculation (dpi), 10 spikelets (in addition to the inoculated spikelet, 4 lower and 5 upper ones) were scored for disease symptoms (necrosis or bleaching). The disease rate is expressed as percentage of symptomatic spikelets among the 10 scored spikelets. All infection assays were repeated twice. Each repetition included six wheat plants per experimental variant. Results from all 12 plants were used for data analysis.

Analysis of in planta produced mycotoxin levels. Inoculated wheat spikelets were individually harvested, weighed, frozen in liquid nitrogen, and stored at $-70^{\circ} \mathrm{C}$. Spikelets were individually lyophilized for $20 \mathrm{~h}$ (Beta 1-B; Christ GmbH, Osterode, Germany) and ground with four tungsten-carbide beads in a TissueLyser (Qiagen $\mathrm{GmbH}$, Hilden, Germany) for 3 min at maximum speed. Next, $2 \mathrm{ml}$ of $84 \%$ (vol/vol) acetonitrile (Carl Roth $\mathrm{GmbH}$ $\&$ Co. KG, Karlsruhe, Germany) was added to the powdered samples, which were then horizontally shaken at $23^{\circ} \mathrm{C}$ for $4 \mathrm{~h}$. After centrifugation for $10 \mathrm{~min}$ at $5,000 \times g, 1.7 \mathrm{ml}$ of the supernatant was transferred to a $15-\mathrm{ml}$ tube. The precipitate was resuspended in $1.7 \mathrm{ml}$ of fresh solvent, extracted for an additional $16 \mathrm{~h}$, and separated from the extract by centrifugation. Both extracts were combined, yielding $3.4 \mathrm{ml}$ of extracts for each of 12 individual spikelets for all experimental variants. Acetonitrile extracts were stored at $-20^{\circ} \mathrm{C}$ until mycotoxin quantification by high-performance liquid chromatograph mass spectrometry (HPLC-MS).

NIV concentration was determined by HPLC with a triple quadrupole detector (Varian $\mathrm{GmbH}$, Darmstadt, Germany) in filtered crude extracts diluted 1:10 with column equilibration buffer. A polar-modified RP-18 column (Polaris C18-Ether, $3 \mu \mathrm{m}$, 100 by $2 \mathrm{~mm}$; Varian $\mathrm{GmbH}$ ) maintained at $40^{\circ} \mathrm{C}$ was used. The flow rate was set to $0.2 \mathrm{ml} / \mathrm{min}$ and the injected volume was $10 \mu \mathrm{l}$. A binary gradient with $5 \%$ acetonitrile in water as solvent $\mathrm{A}$ and methanol as solvent B were used as follows: 0 to $1 \mathrm{~min}, 20 \%$ solvent $\mathrm{B}$; 1 to $8.5 \mathrm{~min}, 20$ to $40 \%$ solvent $\mathrm{B}$; 8.5 to $10.5 \mathrm{~min}, 40$ to $98 \%$ solvent $\mathrm{B}$; followed by washing with $98 \%$ solvent $\mathrm{B}$ and reequilibration with $20 \%$ solvent $\mathrm{B}$. Tandem mass spectrometry (MS/MS) detection was carried out using a Varian 1200LC triple quadrupole with negative electrospray ionization (Varian $\mathrm{GmbH}$ ). Gas temperature and pressure were set to $200^{\circ} \mathrm{C}$ and 18 psi. Needle, shield, and capillary voltage were $-3,500,-600$, and $-40 \mathrm{~V}$, respectively. Fragmentation was performed in a collision cell filled with argon gas (1.3 mTorr). Quantitative determination was performed in single reaction monitoring with a dwell time of $1 \mathrm{~s}$ and a width of $0.7 \mathrm{~m} / \mathrm{z}$ unit, using the transition $311>281$. Quantification of ZEA by HPLC-MS/MS was performed on filtered, defatted crude extracts diluted 1:1 with the mobile phase as described previously (1). Acetonitrile extracts of healthy spikelets amended with NIV (5 to $1,000 \mathrm{ng} / \mathrm{ml}$ ) and ZEA (5 to $320 \mathrm{ng} / \mathrm{ml}$ ) in three repetitions were used for calibration.

Extraction and quantification of fungal DNA in infected spikelets. Ground spikelets that had previously been used for mycotoxin extraction (see above) were dried in a vacuum centrifuge (Univapo100H; UniEquip GmbH, Martinsried, Germany) overnight to remove residual acetonitrile. Extraction of genomic DNA was conducted as reported (6) with modifications as follows. Ground plant samples were blended in $1 \mathrm{ml}$ of cetyltrimethylammonium bromide (CTAB) extraction buffer $(10 \mathrm{mM}$ Tris, $20 \mathrm{mM}$ EDTA, $1.4 \mathrm{M} \mathrm{NaCl}, 2 \%$ [wt/vol] CTAB, and $1 \%$ [wt/vol] polyvinylpyrrolidone, $\mathrm{pH} 8.0$ ), $20 \mu \mathrm{g}$ of proteinase $\mathrm{K}$, and $5 \mu$ of mercaptoethanol. After mixing thoroughly, the samples were incubated for $30 \mathrm{~min}$ at $42^{\circ} \mathrm{C}$ followed by incubation for $30 \mathrm{~min}$ at $65^{\circ} \mathrm{C}$. Mixing continued intermittently every $10 \mathrm{~min}$. The samples were then shaken vigorously with $800 \mu \mathrm{l}$ of chloroform-isoamyl alcohol (24:1), incubated on ice for $15 \mathrm{~min}$, and centrifuged at $10.000 \times g$ for $10 \mathrm{~min}$. The supernatant $(600 \mu \mathrm{l})$ was mixed with $200 \mu \mathrm{l}$ of $30 \%$ (vol/vol) PEG 6000 and $100 \mu \mathrm{l}$ of $5 \mathrm{M} \mathrm{NaCl}$ and centrifuged for $15 \mathrm{~min}$ at $14,000 \times \mathrm{g}$. Pellets were washed twice with $70 \%$ ethanol, dried, and resuspended in $50 \mu \mathrm{l}$ of Tris-EDTA buffer (10 mM Tris, $1 \mathrm{mM}$ EDTA, $\mathrm{pH}$ set to 8.0 with $\mathrm{HCl})$. Subsequent species-specific qPCR analysis for $F$. graminearum was performed as described (6).

Statistical analysis. The Student-Newman-Keuls test (33) was used to determine significant variations between all strains. Statistical comparisons between different treatments of the same strain employed the two-sided $t$ test. Correlations were evaluated by calculation of Pearson's correlation coefficient $(r)$. In all cases, a confidence limit of $95 \%(P<0.05)$ was considered significant. All statistical analyses used the XLSTAT program (version 2008; Addinsoft Deutschland, Andernach, Germany).

\section{RESULTS}

Adaptation of $\boldsymbol{F}$. graminearum to tebuconazole. We investigated the adaptation of $F$. graminearum to relatively high but sublethal fungicide concentrations without the influence of mutagens in order to determine potential outcomes of selection on 
spontaneous genetic alterations. In preliminary experiments, we determined that tebuconazole at $10 \mathrm{mg} / \mathrm{liter}$ was a suitable concentration because it restricted mycelial growth of the $F$. graminearum strain NRRL 13383 to $95 \%$ (data not shown). After adaptation, the mycelia were transferred to MBB to induce conidiation. Conidia were allowed to grow on PDA amended with tebuconazole at $10 \mathrm{mg} / \mathrm{liter}$. Whereas spores derived from a control culture were unable to form a mycelium, the conidia derived from tebuconazole-adapted cultures efficiently formed new colonies. In two out of four repetitions of this adaptation procedure, two types of distinct colonial morphologies, designated phenotype $1(\mathrm{P} 1)$ and phenotype $2(\mathrm{P} 2)$, were found (Fig. 1A). Colonies of $\mathrm{P} 1$ arose at a frequency of $15 \%$, respectively $19 \%$ whereas, in the other cultures, only P2 colonies occurred. On unamended medium, P1 isolates exhibited a colony morphology that closely resembled that of the nonadapted parental strain, which is characterized by a dense aerial mycelium. In contrast, P2 isolates produced aerial mycelia that were less dense (Fig. 1B). The P1 isolates grew on fungicide-amended agar with an extensive aerial mycelium, whereas P2 isolates grew flat on the agar with few aerial hyphae (Fig. 1C). For further experiments aiming to characterize these adapted phenotypes in detail, three isolates of each (P1-1, P1-9, and P1-11 and P2-1, P2-4, and P2-8) were chosen arbitrarily.

Evaluation of fungicide sensitivities of NRRL 13383 and adapted isolates. The levels of resistance to tebuconazole were determined quantitatively by measuring radial growth and conidial germination rates of the parental strain NRRL 13383 and adapted isolates at increasing tebuconazole concentrations (Table 1). In both assays, all adapted isolates tested exhibited significantly $(P<0.05)$ increased ED values compared with NRRL 13383 with the exception of the $\mathrm{ED}_{50}$ values of the P2 isolates in mycelial growth assays. Resistance factors (RFs) determined by the germination assays varied little between the P1 and P2 isolates. In contrast, the mycelial growth assays revealed consistently higher RF values of the P1 isolates.

To evaluate the mitotic stability of fungicide-adapted phenotypes, the isolates were subjected to additional cycles of mycelial growth and sporulation. For the sixth vegetative generation, mycelial growth and spore germination were assayed as before (Table 1). Except for isolate P1-9, that showed a decrease in $\mathrm{ED}_{50}$ in the mycelial growth assay, mostly minor changes were obtained compared with those obtained previously. We conclude that phenotypes P1 and P2 differ not only in morphology but also in the degree of tebuconazole resistance, and that this resistance is mitotically stable.

Cross-resistance in tebuconazole-adapted isolates to additional fungicides was qualitatively assessed by discriminatory dose screens (Fig. 2). We tested the two azole fungicides prothioconazole (subclass triazoles) and prochloraz (subclass imidazoles), as well as the two amine fungicides, spiroxamine (subclass spiroketalamines) and fenpropimorph (subclass morpholines). The strobilurine azoxystrobin was also tested but it was unable to significantly inhibit NRRL 13383 even when applied at a concentration of $\leq 800 \mathrm{mg} / \mathrm{liter}$ (data not shown). For the other fungicides, we determined discriminatory doses as minimal inhibitory concentrations for the parental isolate NRRL 13383. This assay revealed that all adapted isolates exhibited positive crossresistance to at least one of the two fungicide classes tested. Interestingly, the P2 isolates displayed increased tolerance not only for both azoles but also for the two amine fungicides. Thus, P2 may be referred to as a multidrug-resistance (MDR) phenotype. Positive cross-resistance of the P1 isolates was confined to azoles. Additional screens with the P1 isolates on lower concentrations of spiroxamine and fenpropimorph did not indicate negative cross-resistance effects (data not shown). With respect to resistance to the three azole fungicides tested in this work, P1 isolates grew better than P2 isolates, especially in the presence of the triazoles used. In contrast, the P2 isolates exhibited better growth on the imidazole prochloraz.

Characterization of fitness and virulence. To examine differences in fitness between the fungal isolates, growth rates on fungicide-free PDA were determined at four temperatures (Fig. 3A). All P1 isolates grew rather similarly to NRRL 13383 at all temperatures tested. In contrast, the P2 isolates grew significantly $(P<0.05)$ slower than NRRL 13383 and the P1 isolates at 23 and $30^{\circ} \mathrm{C}$. At lower temperatures, the fitness impairment of the $\mathrm{P} 2$ isolates was generally lower and almost not apparent at $7{ }^{\circ} \mathrm{C}$. Additionally, we assessed two other aspects of fungal fitness (i.e., the capacity to produce macroconidia and their germination rate). The growth-impaired P2 isolates and the P1 isolates produced amounts of macroconidia similar to the parental strain (Fig. 3B). Germination rates of all isolates were very similar, close to $100 \%$.

We further analyzed the effect of in vitro azole adaptation on fungal virulence on wheat heads. NRRL 13383 and its adapted descendants were assayed by inoculation of one central spikelet within individual wheat heads, and virulence was assessed by evaluating the spread of symptoms to the neighboring spikelets. The spread of symptoms has been reported to correlate with fungal spread and reflects virulence (23). As an independent measure, virulence was evaluated by the fresh weight of the inoculated spikelets after harvest. These assays were performed both with and without the application of tebuconazole. For each strain analyzed, fungicide application significantly $(P<0.05)$ reduced the spread of symptoms (Fig. 4A) and the loss of spikelet fresh weight (Fig. 4B). The fresh weights of all inoculated

TABLE 1. Sensitivity of Fusarium graminearum NRRL 13383 and tebuconazole-adapted isolates to tebuconazole

\begin{tabular}{|c|c|c|c|c|c|c|c|c|c|c|c|c|}
\hline \multirow[b]{3}{*}{$\begin{array}{l}\text { Description, } \\
\text { isolate }^{\mathrm{Z}}\end{array}$} & \multicolumn{6}{|c|}{ Mycelial growth assay } & \multicolumn{6}{|c|}{ Spore germination assay } \\
\hline & \multicolumn{3}{|c|}{ Second generation } & \multicolumn{3}{|c|}{ Sixth generation } & \multicolumn{3}{|c|}{ Second generation } & \multicolumn{3}{|c|}{ Sixth generation } \\
\hline & $\begin{array}{c}\mathrm{ED}_{50} \\
\text { (mg/liter) }\end{array}$ & $\begin{array}{c}\mathrm{ED}_{90} \\
\text { (mg/liter) }\end{array}$ & RF & $\begin{array}{c}\mathrm{ED}_{50} \\
\text { (mg/liter) }\end{array}$ & $\begin{array}{c}\mathrm{ED}_{90} \\
\text { (mg/liter) }\end{array}$ & $\mathrm{RF}$ & $\begin{array}{c}\mathrm{ED}_{50} \\
\text { (mg/liter) }\end{array}$ & $\begin{array}{c}\mathrm{ED}_{90} \\
\text { (mg/liter) }\end{array}$ & RF & $\begin{array}{c}\mathrm{ED}_{50} \\
\text { (mg/liter) }\end{array}$ & $\begin{array}{c}\mathrm{ED}_{90} \\
\text { (mg/liter) }\end{array}$ & RF \\
\hline \multicolumn{13}{|l|}{ Nonadapted } \\
\hline \multicolumn{12}{|l|}{ Adapted P1 } & n.a. \\
\hline P1-1 & $0.48 \pm 0.03 b$ & $28.32 \pm 1.22 \mathrm{~d}$ & 3.4 & $0.50 \pm 0.02 \mathrm{bc}$ & $22.76 \pm 2.11 \mathrm{bcd}$ & 3.3 & $2.46 \pm 0.12 \mathrm{~d}$ & $3.29 \pm 0.18 \mathrm{~d}$ & 4.0 & $2.37 \pm 0.04 \mathrm{~d}$ & $3.12 \pm 0.05 \mathrm{e}$ & 3.8 \\
\hline P1-9 & $1.52 \pm 0.11 \mathrm{~d}$ & $35.36 \pm 1.56 \mathrm{e}$ & 10.9 & $0.86 \pm 0.08 \mathrm{~d}$ & $30.36 \pm 4.15 \mathrm{~d}$ & 5.7 & $1.60 \pm 0.07 \mathrm{c}$ & $2.73 \pm 0.19 \mathrm{c}$ & 2.6 & $1.53 \pm 0.02 \mathrm{c}$ & $2.43 \pm 0.02 \mathrm{~d}$ & 2.5 \\
\hline P1-11 & $0.73 \pm 0.02 \mathrm{c}$ & $30.73 \pm 1.48 \mathrm{de}$ & 5.1 & $0.61 \pm 0.01 \mathrm{c}$ & $26.56 \pm 1.93 \mathrm{~cd}$ & 4.1 & $1.42 \pm 0.09 \mathrm{bc}$ & $2.19 \pm 0.09 \mathrm{~b}$ & 2.3 & $1.41 \pm 0.07 \mathrm{bc}$ & $2.25 \pm 0.08 \mathrm{~cd}$ & 2.3 \\
\hline \multicolumn{13}{|l|}{ Adapted P2 } \\
\hline $\mathrm{P} 2-1$ & $0.25 \pm 0.01 \mathrm{a}$ & $11.88 \pm 0.82 \mathrm{~b}$ & 1.8 & $0.39 \pm 0.03 b$ & $23.26 \pm 1.22 \mathrm{bcd}$ & 2.6 & $1.21 \pm 0.06 \mathrm{~b}$ & $1.93 \pm 0.11 b$ & 2.0 & $1.45 \pm 0.06 \mathrm{bc}$ & $2.21 \pm 0.11 \mathrm{~cd}$ & 2.4 \\
\hline P2-4 & $0.30 \pm 0.01 \mathrm{a}$ & $17.15 \pm 1.44 \mathrm{c}$ & 2.1 & $0.26 \pm 0.01 \mathrm{a}$ & $17.77 \pm 1.04 \mathrm{bc}$ & 1.7 & $1.24 \pm 0.03 b$ & $2.02 \pm 0.04 \mathrm{~b}$ & 2.0 & $1.25 \pm 0.02 \mathrm{~b}$ & $1.90 \pm 0.02 \mathrm{~b}$ & 2.0 \\
\hline P2-8 & $0.27 \pm 0.02 \mathrm{a}$ & $13.42 \pm 1.22 \mathrm{bc}$ & 1.9 & $0.27 \pm 0.02 \mathrm{a}$ & $13.42 \pm 1.22 \mathrm{~b}$ & 1.7 & $1.34 \pm 0.02 b$ & $2.03 \pm 0.07 \mathrm{~b}$ & 2.2 & $1.33 \pm 0.03 \mathrm{bc}$ & $2.15 \pm 0.04 \mathrm{c}$ & 2.2 \\
\hline
\end{tabular}

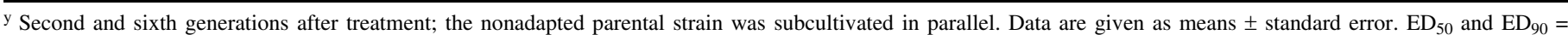
effective doses leading to a 50 or $90 \%$ inhibition, respectively. Means (within a column) designated by the same letter are considered not to be significantly different by the SNK-test at $P<0.05$. Resistance factor (RF) is the ratio of the $\mathrm{ED}_{50}$ value of an adapted strain to $\mathrm{ED}_{50}$ of NRRL 13383; n.a. $=$ not applicable.

${ }^{\mathrm{z}} \mathrm{P} 1$ and $\mathrm{P} 2=$ adapted phenotypes 1 and 2 , respectively. 
A
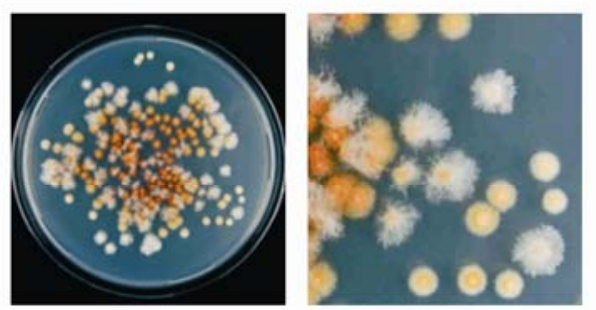

B
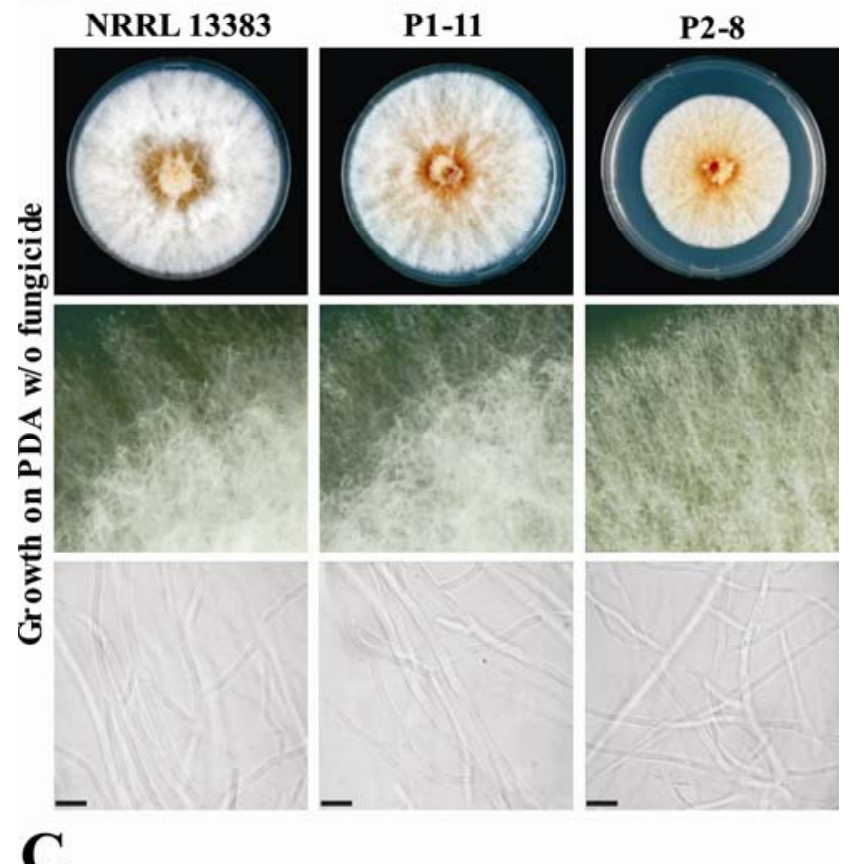

NRRL 13383

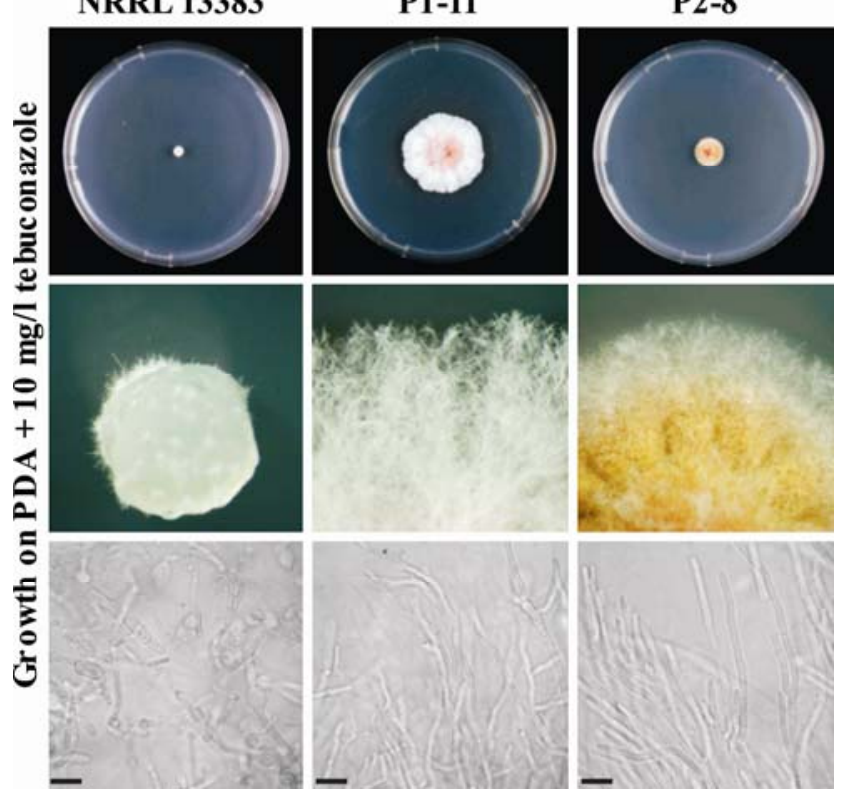

Fig. 1. Colonial and hyphal morphologies of Fusarium graminearum NRRL 13383 and descendants obtained after adaptation to tebuconazole at $10 \mathrm{mg} / \mathrm{liter}$. A, Morphologically distinct fungal colonies arose after adaptation. A conidial suspension (200 conidia in $100 \mu \mathrm{l}$ ) that was derived from an adapted mycelium was streaked onto potato dextrose agar (PDA) plates (145 $\mathrm{mm}$ in diameter) amended with tebuconazole at $10 \mathrm{mg} /$ liter and incubated at $23^{\circ} \mathrm{C}$ for 9 days. B and C, Mycelia of NRRL 13383, P1-11, and P2-8 grown on PDA plates B, without and $\mathbf{C}$, with tebuconazole at $10 \mathrm{mg} /$ liter. Plates were centrally inoculated with an agar plug and grown at $23^{\circ} \mathrm{C}$ for 7 days. Photographs were taken from mycelia (upper two rows) and from hyphal fronts (lower rows). Magnification was $3 \times$ (middle rows) and 600× (lower rows). Black bars represent $20 \mu \mathrm{m}$. variants differed significantly from the noninoculated control (Fig. 4B). NRLL 13383 and the P1 and P2 isolates did not differ significantly $(P>0.05)$ in their ability to spread disease symptoms below and above the point of inoculation, although the P2 isolates appeared less virulent when the fungicide was omitted (Fig. 4A). Furthermore, fresh weight reductions caused by the P2 strains were often significantly less severe than those caused by NRRL 13383 and the P1 strains when the fungicide was omitted (Fig. 4B). The same trend was also evident in the presence of tebuconazole, even though not supported by statistics for most comparisons.

In summary, P1 and P2 isolates differed not only in morphology but also with respect to fitness and virulence. Whereas P1 strains exhibited only minor variations from strain NRRL 13383, the P2 strains showed growth deficits and reduced virulence.

Analysis of mycotoxin accumulation in planta. Whether the adaptation to fungicides influences mycotoxin production is of major interest for agronomy. To address this question, the inoculated spikelets assessed in the virulence assays were individually used to extract and analyze mycotoxins by HPLC-MS. Additionally, after mycotoxin determination, the same spikelets were also used to extract total DNA to quantify $F$. graminearum by qPCR. This allowed relating the amount of mycotoxins found in each spikelet analyzed to (i) its fresh weight (Fig. 4C and E) and (ii) the amount of Fusarium DNA, reflecting fungal biomass (Fig. 4D and F). Importantly, this experimental design allowed direct comparison of the effects of fungicide treatments of adapted and nonadapted strains on mycotoxin production in planta.

In all variants analyzed, considerable levels of the trichothecene NIV were detected. In all spikelets inoculated in the absence of the fungicide, the adapted P1 isolates showed higher NIV levels than their parent NRRL 13383, whereas infections with P2 isolates yielded lower NIV levels. Although, when expressed as absolute NIV contents, such differences could statistically not be proven $(P>0.05)$ (Fig. 4C), some data were more distinct when expressed as relative NIV productivity (i.e., mycotoxin production per unit of fungal DNA) (Fig. 4D). Isolate P1-9 produced significantly more NIV per fungal biomass than NRRL 13383. Moreover, the comparison of P1 and P2 isolates showed significant differences for NIV productivity in several cases. Fungicide application significantly $(P<0.05)$ reduced NIV contents in the inoculated spikelets for each individual strain when compared with the corresponding variants without the fungicide (Fig. 4C). However, for assessments of NIV productivity (Fig. 4D), tebuconazole application resulted in a significant reduction only for NRRL $13383(P=0.045)$ and P1-9 $(P=0.019)$. When comparing the fungicide-treated isolates with each other, P1 again exhibited higher NIV contents (Fig. 4C) and higher NIV productivity (Fig. 4D) than NRRL 13383 and the P2 isolates. Isolate P1-11 had significantly higher NIV productivity compared with the parental strain but also with P2-4 and P2-8.

In addition to the trichothecene NIV, the polyketide mycotoxin ZEA was detected in $56.5 \%$ of all samples analyzed. ZEA amounts exhibited a high variability between different spikelets that were infected by the same fungal strain, rendering statistical evaluation of differences among strains and treatments impossible (Fig. 4E and F). Interestingly, the average ZEA quantity of all fungicide-treated samples was higher $(174.8 \pm 440.6 \mathrm{ng})$ compared with the untreated samples $(78.6 \pm 306.1 \mathrm{ng})(P=0.103)$.

Taken together, the mycotoxin analyses revealed further differences between the two adapted phenotypes. P1 strains tended to produce more and P2 strains produced less NIV than their parent NRRL 13383. ZEA levels tended to be generally higher in samples treated with the fungicide.

Correlation analyses. The association of the fresh weight of the inoculated spikelet with virulence, fungal biomass, and mycotoxin contents was assessed by scatter plots that used the averaged data from each individual isolate. Virulence, expressed as symp- 
toms that had spread from a single inoculated spikelet, showed a highly significant negative correlation with the losses of fresh weight (Fig. 5A). This supported the suitability of fresh weight measurements for assessing virulence of Fusarium strains in the performed infection assay. Both with and without tebuconazole application, the P1 isolates always clustered with NRRL 13383, whereas the P2 isolates always formed a distinct cluster. Furthermore, the effectiveness of the fungicide to limit symptom spread was evident because the clusters of the treated and untreated isolates were clearly separated. To test whether the reduction of spikelet fresh weight depended more on mycotoxin contents than solely on fungal biomass, we assessed further correlations. We observed a highly significant negative correlation of spikelet fresh weight to NIV contents (Fig. 5C) but no correlation to fungal biomass (Fig. 5B). There was no indication that ZEA contents may have affected the fresh weight of the inoculated spikelets (correlation not significant) (Fig. 5D).

\section{DISCUSSION}

Due to the prevalence of azoles in the control of fungal pathogens, it is important to assess the risk of the emergence of and to investigate the mechanisms leading to azole resistance. In this work, we addressed the potential to generate in vitro acquired resistance in $F$. graminearum NRRL 13383 and studied the effects of adaptation in the obtained strains. Exposure to tebuconazole at $10 \mathrm{mg} / \mathrm{liter}$ for 33 days resulted in the emergence of two morphologically distinct phenotypes differing in the degree of resistance to tebuconazole. In addition, these phenotypes also differed in general fitness, cross-resistance against other fungicides, and virulence and mycotoxin levels in wheat.

Laboratory experiments are well suited to investigate mechanisms of the evolution of fungicide resistance, because it is possible to easily replicate them, to control the strength of selection, and to use defined reference strains (11). Fungicide-resistant strains can be generated in vitro by several approaches, such as short exposures to UV light or chemical mutagens to introduce mutations. Furthermore, selection of spontaneous genetic alterations can be achieved by continuous exposure of fungal mycelia to sublethal fungicide concentration. This approach, which is referred to as adaptation, was used in this study.

As determined by mycelial growth assays, the P1 and P2 isolates differ in the RF to tebuconazole that had increased through adaptation up to 10.9- and 2.1-fold, respectively, compared with the base level in F. graminearum NRRL 13383 (Table 1). Similar levels of resistance had been described for UV-induced mutants of Nectria haematococca var. cucurbitae to the DMIs fenarimol ( $\mathrm{RF} 2.0$ to 4.0), triadimenol ( $\mathrm{RF} 5.1$ to 8.0), and imazalil (RF 2.0 to 4.0) (28) and, in another report using the same experimental system, to tebuconazole (RF 4.0 to 15.7), flusilazole (RF 1.8 to 11.7), penconazole (3.3 to 5.7), imazalil (RF 2.0 to 6.5), and prochloraz (RF 2.0 to 9.4) (2). In Pseudocercosporella herpotrichoides, UV mutagenesis allowed for the recovery of strains with RF values to prochloraz of 1.5 to 19.8 (27). From large numbers of spores of Penicillium italicum, fenarimol-resistant strains were obtained with RF values of 15 to 50 (17).
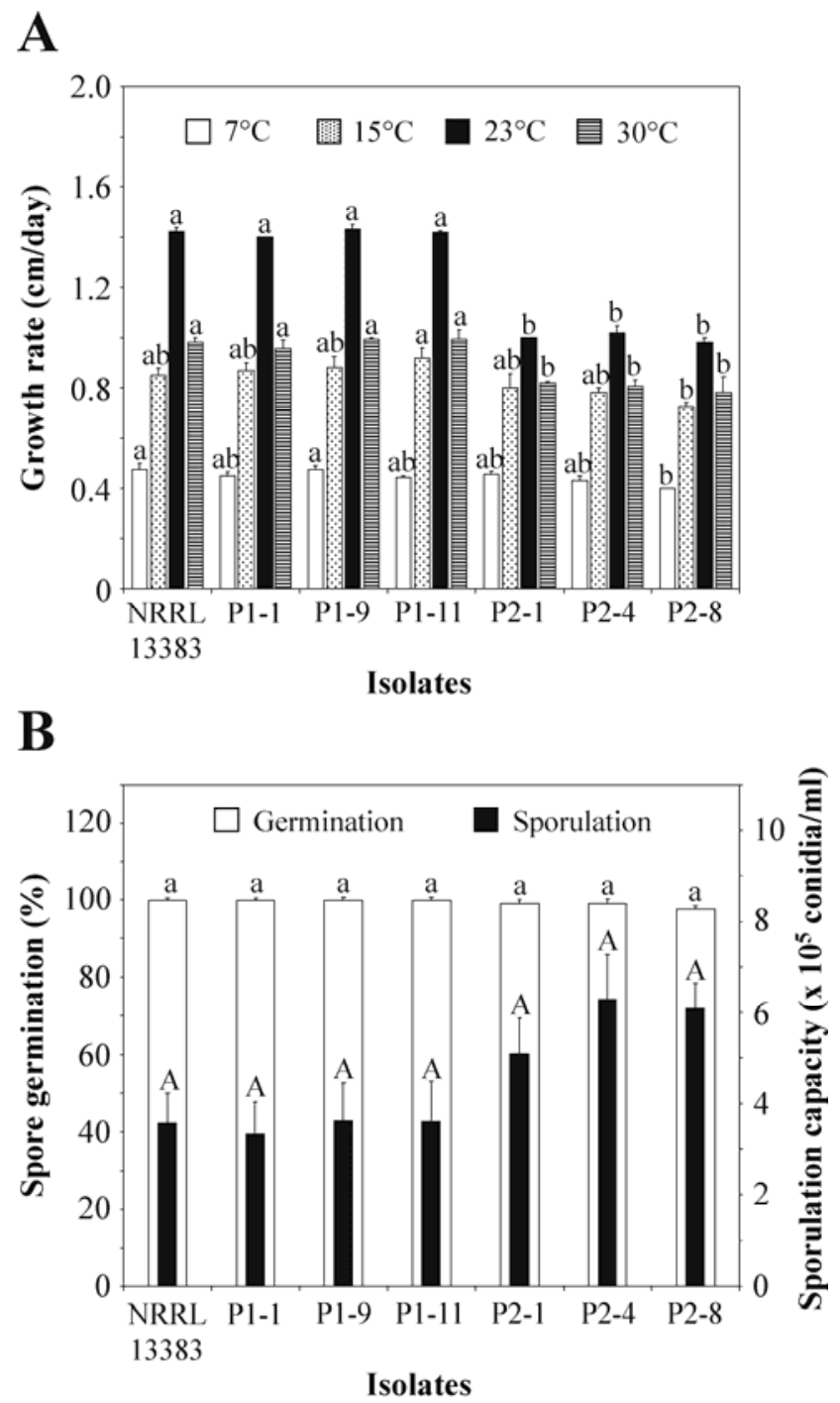

Fig. 3. Fitness parameters of Fusarium graminearum NRRL 13383 and adapted descendants. A, Growth rates on potato dextrose agar at indicated temperatures. B, In vitro spore formation capacity (black bars) and spore germination frequency (white bars). Columns represent the means of five and three replicates, respectively. The error bars indicate standard errors. For comparison of the isolates within one treatment, letters give groups of means that were determined by multiple comparisons using the Student-NewmanKeuls test. Different letters indicate significant differences at $P<0.05$.
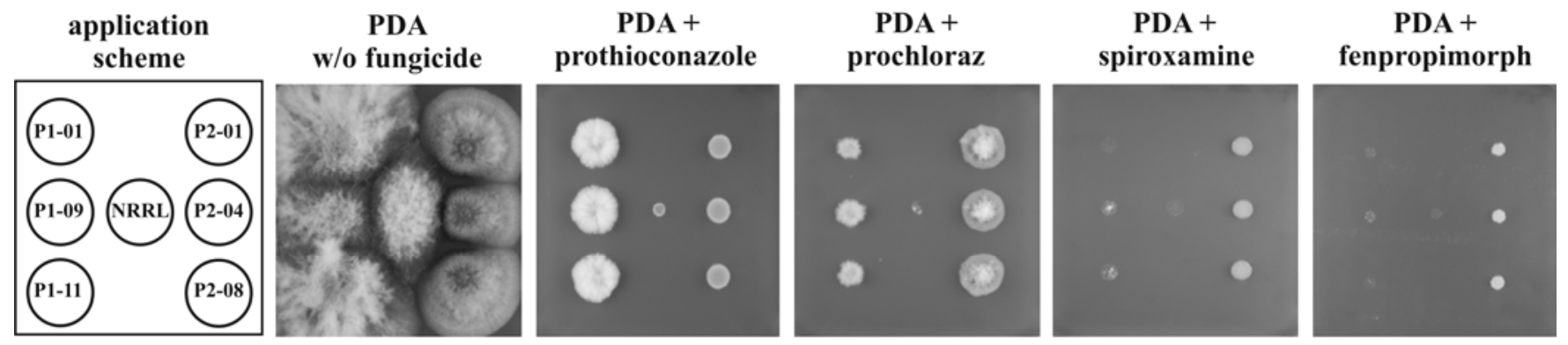

Fig. 2. Evaluation of cross-resistance of the adapted isolates. Conidial suspensions (2,000 conidia in $2 \mu 1)$ were applied on potato dextrose agar (PDA) plates amended with concentrations of fungicides previously optimized for discrimination (i.e., prochloraz at $0.15 \mathrm{mg} /$ liter, prothioconazole at $15 \mathrm{mg} / \mathrm{liter}$, spiroxamine at $285 \mathrm{mg} / \mathrm{liter}$, and fenpropimorph at $100 \mathrm{mg} / \mathrm{liter}$ ). Plates were incubated at $23^{\circ} \mathrm{C}$ for 7 days. 
Previous adaptation experiments on Colletotrichum graminicola to tebuconazole (47) and Ustilago maydis to triadimefon (49) started with low doses that were gradually increased, which yielded isolates with RF values of up to 7.2 and 42, respec- tively. For $U$. maydis, a correlation was observed between the number of the gradually intensified fungicide treatments and the degree of the acquired resistance (49). Thus, resistance levels against azole fungicides cover some range and vary with the
A

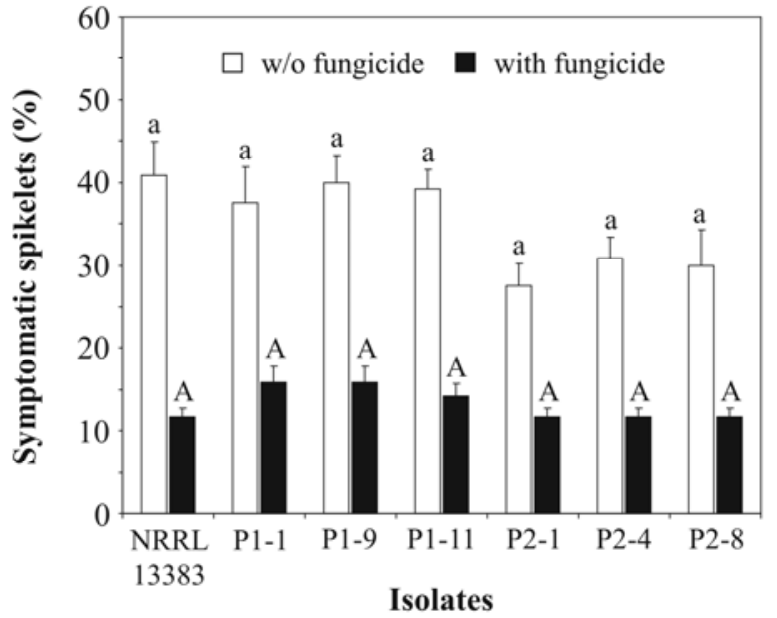

C

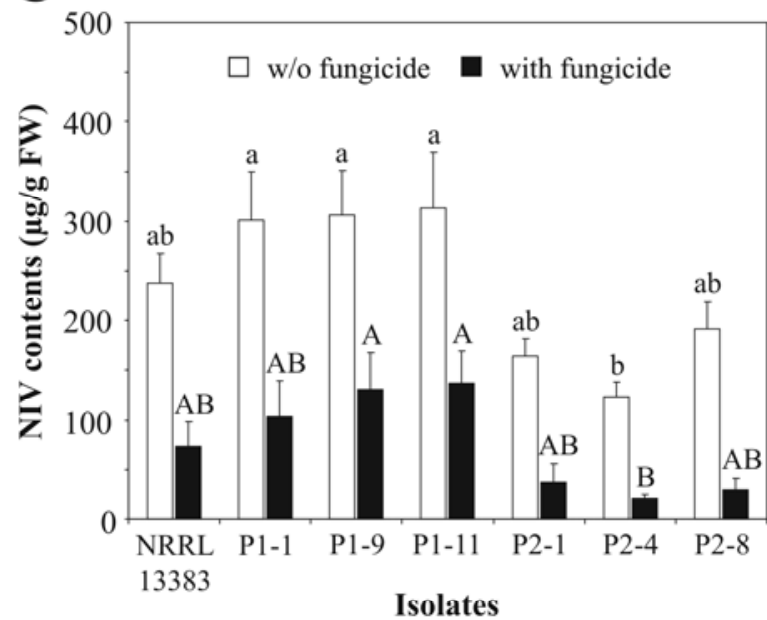

$\mathbf{E}$

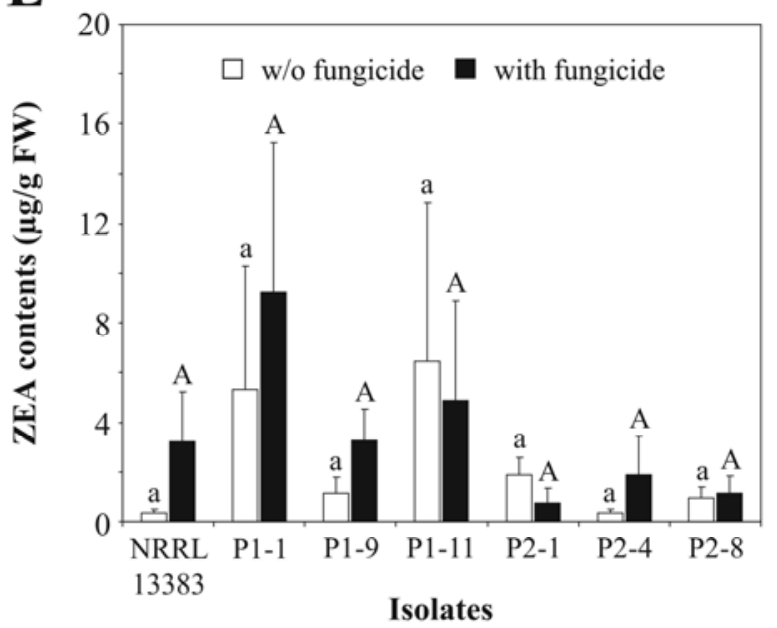

B

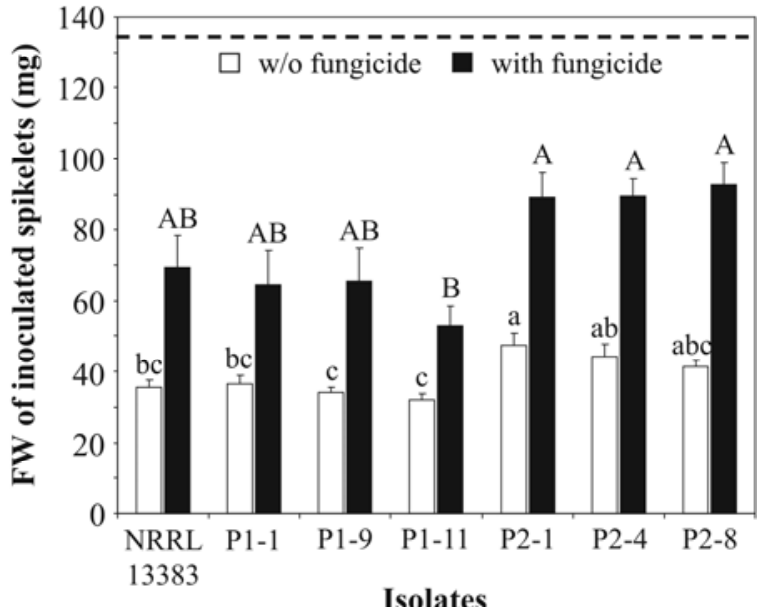

D

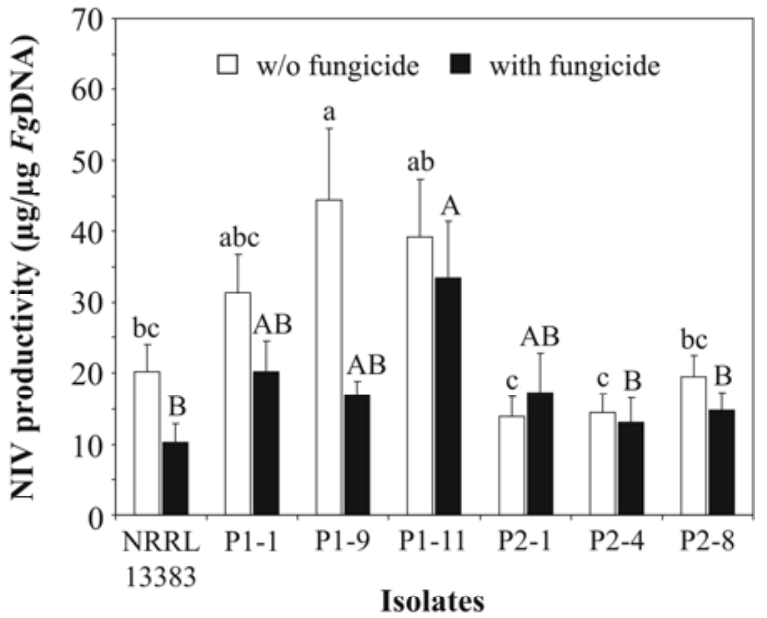

$\mathbf{F}$

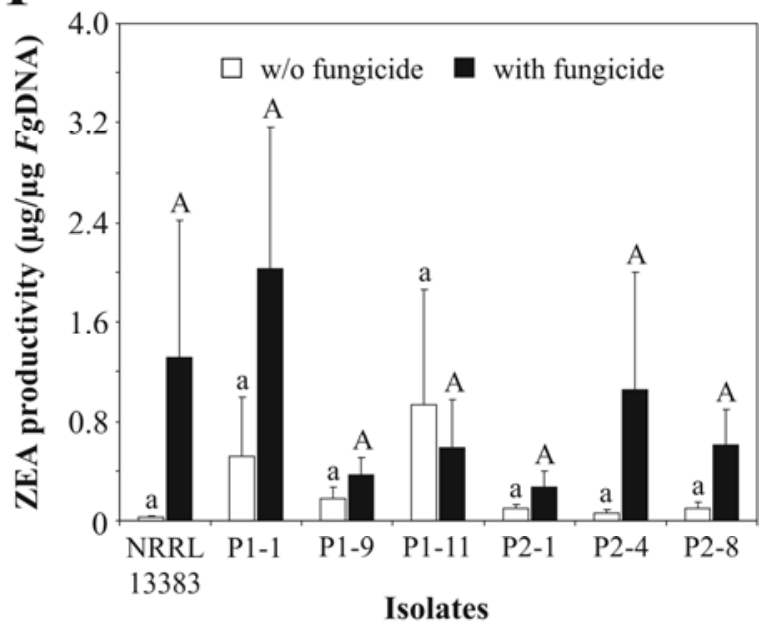

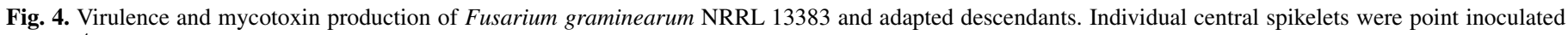

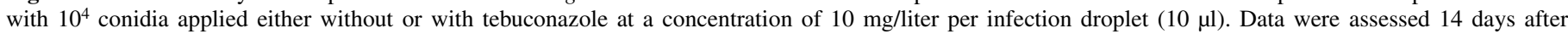

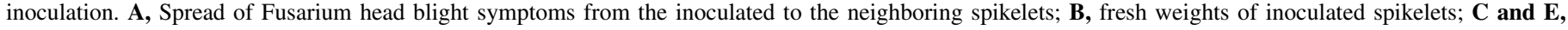

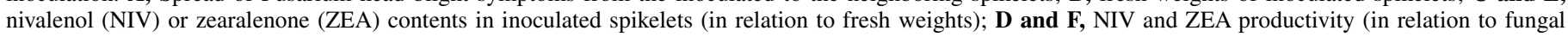

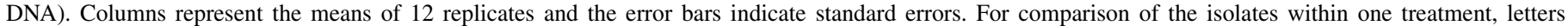

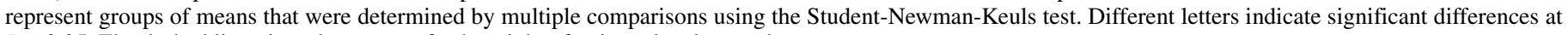
$P<0.05$. The dashed line gives the average fresh weight of uninoculated controls. 
species, the fungicide, and the approach employed to select for resistance.

Whereas the P1 isolates grow in vitro as well and are as virulent on spring wheat as NRRL 13383, the P2 isolates grow more slowly at higher temperatures and appeared less virulent. Although we have determined significant differences in fungicide sensitivity of the P1 and P2 strains and their parent in vitro, the differences observed for virulence on spring wheat treated with tebuconazole were statistically not supported. Nevertheless, P1 isolates appeared somewhat more virulent and the P2 isolates appeared less virulent than NRRL 13383. This discrepancy between the results of in vitro and in planta fungicide treatments could be due to several reasons. In planta, the inhibitory effect of tebuconazole may be more critical because the fungus has to cope not only with the fungicide but also with a reduced supply of nutrients and with host defense reactions. These additional stress factors may overrule the benefits of fungicide resistance and, thus, may mask the differences in fungicide sensitivity between NRRL 13383 and the adapted strains. For comparison, mutants of $P$. italicum (19) and Pseudocercosporella herpotrichoides (27) that showed high resistance levels in vitro were similarly resistant against the fungicide when this was applied onto the infected hosts (i.e., orange or wheat). However, in both cases, the fungicide was applied curatively $24 \mathrm{~h}$ or 4 days after inoculation. Therefore, the rather minor resistance effects we have observed in planta could also be a consequence of the inoculation procedure. In our experiments, tebuconazole was applied together with the conidia directly into the spikelets and, therefore, was already effective during conidial germination. Because the $\mathrm{ED}_{90}$ values were consistently higher in the mycelial growth assays than in the spore germination assays, it is possible that germinating spores were subjected to a high level of stress in the spikelet. In the field, a scenario of the concurrent arrival of conidia and the fungicide at the spikelet may appear rarely and, therefore, practical resistance levels of our adapted isolates may be underestimated. Nevertheless, the inoculum and the fungicide were applied concomitantly to ensure reproducibility in the subsequent mycotoxin and qPCR analyses.

Another difference between the tebuconazole-adapted P1 and P2 isolates was discovered for cross-resistance against additional fungicides. The P1 isolates exhibited positive cross-resistance only to the azole fungicides prothioconazole and prochloraz but not to the amine fungicides fenpropimorph and spiroxamine. Amines, like the azoles, target sterol-biosynthesis but inhibit different enzymes (i.e., sterol $\Delta 14$-reductase or sterol $\Delta 8 \rightarrow \Delta 7$ isomerase) (13). In contrast, P2 isolates acquired resistance to all azoles and both amines tested. In azole-resistant strains analyzed in other species, cross-resistance to amine fungicides was only sometimes observed. Some azole-resistant mutants of $U$. maydis were also resistant against fenpropimorph (50), whereas others (5), as well as mutants of Penicillium italicum $(17,18)$ and $N$. haematococca $(2,28)$, displayed no cross-resistance or were even more sensitive.

We propose that the P1 isolates may have developed mechanisms mediating resistance to azoles, whereas the P2 isolates may employ rather nonspecific mechanisms that allow tolerating fungicides by different modes of action. MDR found in P2 isolates of $F$. graminearum is well documented in other plantpathogenic fungi. Typically, MDR is based on enhanced activity of efflux transporters $(15,42)$. Based on several studies, it was assumed that impairment of fitness and virulence of resistant strains could be attributed to increased energy demand for active fungicide efflux (8). However, studies on energy-dependent efflux-mediated fungicide resistance in $N$. haematococca rendered varying results. Whereas the mutants that were resistant to fenarimol showed reduced growth rates and virulence (28), those resistant to tebuconazole were not impaired (2). Furthermore, fitness defects could not be detected in fungicide-resistant $P$. italicum strains with enhanced fungicide efflux activity $(17,18)$. In this context, it should be considered that the P2 isolates showed growth retardation only at higher temperatures, which might indicate that the sterol composition could be modified. Interest-
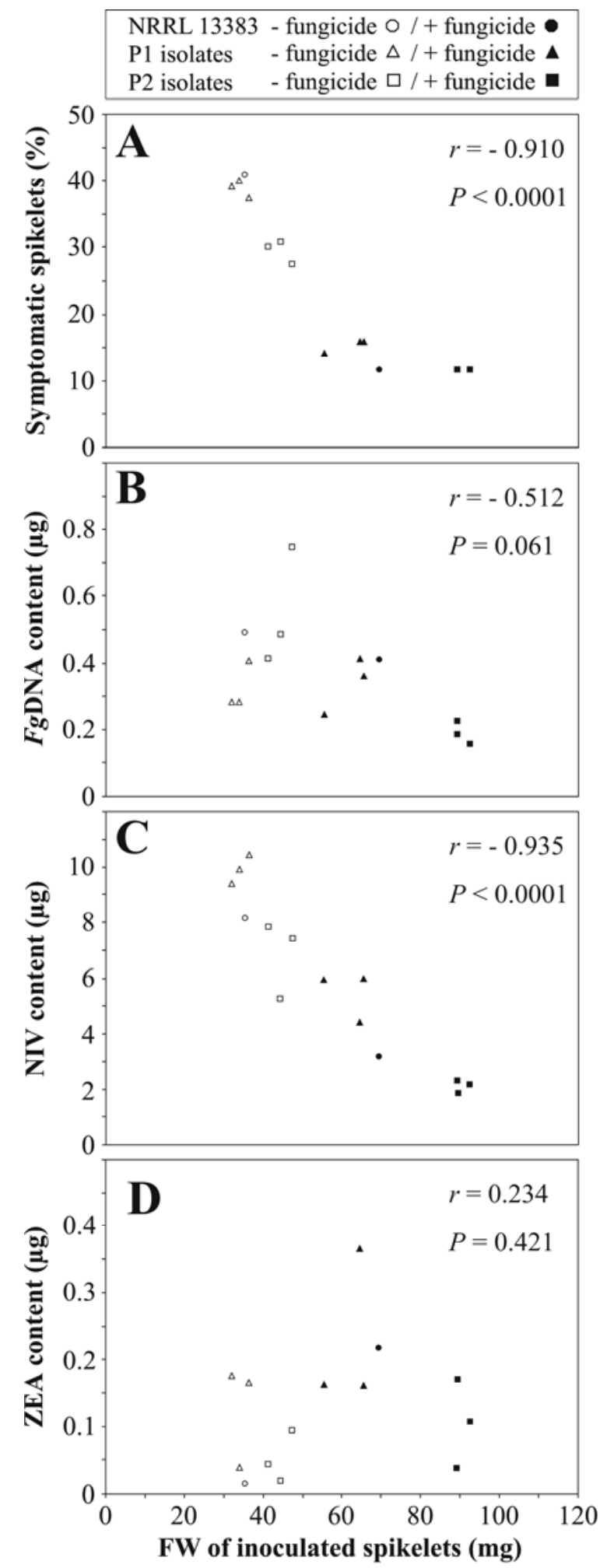

Fig. 5. Scatter plots showing the correlation between the mean fresh weights (FW) of the inoculated spikelets and the means of the $\mathbf{A}$, percentage of symptomatic spikelets; B, amount of fungal DNA in the spikelets; $\mathbf{C}$, nivalenol (NIV) content of the spikelets; and D, zearalenone (ZEA) content of the spikelets. Data were assessed 14 days after inoculation. Calculated Pearson's correlation coefficient $(r)$ and the respective probability $(P)$ for correlation are given. 
ingly, an azole-resistant field isolate of $M$. graminicola showed altered membrane sterol composition, which may result in reduced fungicide accumulation and growth rates (25). Furthermore, it has been shown that membrane sterol composition affects localization and function of efflux transporters (37).

Because of their azole-specific resistance, we presumed, for the P1 isolates, amino acid exchanges in CYP51. Various studies on different fungal species have shown that several point mutations in the CYP51 gene may mediate azole resistance $(31,51)$. The genome of $F$. graminearum harbors three genes putatively encoding sterol 14 $\alpha$-demethylase (FGSG_01000, FGSG_04092, and FGSG_11024). Sequencing of PCR fragments that were amplified from all three genes in the strains $\mathrm{P} 1-11$ and $\mathrm{P} 2-8$ (and F. graminearum NRRL 13383, which was included for comparison) did not reveal any mutation in any of the three genes in the two adapted isolates (data not shown). Therefore, the cause for the resistance in these isolates remains unclear. Likewise, sequence analysis of two of the three $C Y P 51$ genes in Chinese field isolates that were found resistant to tebuconazole and prochloraz did not indicate any aberration associated with DMI resistance (52). However, one advantage of the in vitro approach taken to generate strains with acquired fungicide resistance is that these strains are isogenic descendants of a characterized reference strain which allows for a direct comparison. This will allow gaining deeper insights into the genetics of resistance development for example by microarray analysis.

In addition to the differences in the level of resistance to tebuconazole, fitness, cross-resistance, and virulence, the P1 and $\mathrm{P} 2$ isolates also differ in their potential to produce mycotoxins in infected wheat. The point inoculation used allowed us to determine the mycotoxin contents in reproducibly infected, individual spikelets (23). Furthermore, quantification of $F$. graminearum DNA from the inoculated spikelet by qPCR (6) allowed us to assess the potential of mycotoxin production based on fungal biomass at increased spatial resolution. Spikelets inoculated with the adapted P1 isolates exhibited higher NIV contents than their parent NRRL 13383 in either the absence or the presence of tebuconazole, which was accompanied by higher NIV productivity per fungal biomass. Moreover, the negative correlation of spikelet fresh weight to NIV content underlines the contribution of NIV to virulence of $F$. graminearum in wheat (34). Although the P2 isolates have acquired resistance to tebuconazole, they produce lower NIV contents compared with NRRL 13383, even in the presence of the fungicide. In contrast, the NIV productivity per fungal biomass of P2 strains was not diminished by the fungicide. Thus, it appears that tebuconazole may reduce development of the P2 isolates in planta but not their NIV production. ZEA levels appeared to be higher in fungicide-treated spikelets infected with either the nonadapted strain NRRL 13383 or most of the adapted isolates. ZEA did not affect the fresh weight of the inoculated spikelets, which supported previous reports from barley that a loss of ZEA production did not impede fungal infection and symptom development (32).

Furthermore, our study provides additional insights into processes that may occur in fungicide-treated fields, where selection for general fitness is effective in parallel to selection for higher fungicide resistance. Although P1 isolates were less frequently recovered in vitro than $\mathrm{P} 2$ isolates, fitness advantages could promote the emergence of P1 in field populations. In contrast, although P2 generally appears to be less competitive, it could emerge and survive in field populations when azole and amine fungicides are repeatedly applied as a mixture. Such conditions may prevent the emergence of P1. The contrasting features observed for the P1 and P2 isolates in this study suggest that not only the amount of azoles sprayed onto cereals but also the combination with other fungicides could influence the composition of $F$. graminearum field populations. Therefore, detailed analyses of isolates recovered from field experiments, which were set up to test for this hypothesis, will be interesting. Highlighting another potential risk, it has been shown that sexual recombination occurred with respect to carbendazim resistance in field populations of $F$. graminearum (9). Thus, even if the P1 and P2 traits may arise independently in different individuals in the field, they could be combined by sexual recombination, rendering progeny that do not suffer fitness penalties and that have high resistance to azoles and cross-resistance to amines. Additionally, it might be possible that compensatory mutations could restore fitness in P2 strains without losing resistance, as has been previously described for fungicide-resistant Aspergillus nidulans strains (45).

In conclusion, our work suggests that $F$. graminearum is able to adapt to azole fungicides. Our study shows that certain adapted isolates produced increased NIV levels in grains under defined conditions. Therefore, it is essential to analyze whether a correlation exists between acquired azole resistance and increased mycotoxin levels not only in laboratory strains but also in field populations. Thus, monitoring of $F$. graminearum field populations with respect to fungicide resistance and mycotoxin production is important.

\section{ACKNOWLEDGMENTS}

This work was financially supported by the Ministry of Education of the State of Saxony-Anhalt (PlantResource II/TP3) and the DTg (WI 1054/3-1). We thank E. Vollmer for greenhouse services, D. Jany and A. Beutel for technical assistance, K. O'Donnell for providing the reference strain, and Bayer CropScience AG and BASF SE for kindly providing fungicides.

\section{LITERATURE CITED}

1. Adejumo, T. O., Hettwer, U., and Karlovsky, P. 2007. Survey of maize from south-western Nigeria for zearalenone, alpha- and beta-zearalenols, fumonisin B-1 and enniatins produced by Fusarium species. Food Addit. Contam. 24:993-1000.

2. Akallal, R., Debieu, D., Lanen, C., Daboussi, M. J., Fritz, R., Malosse, C., Bach, J., and Leroux, P. 1998. Inheritance and mechanisms of resistance to tebuconazole, a sterol C14-demethylation inhibitor, in Nectria haematococca. Pestic. Biochem. Physiol. 60:147-166.

3. Bai, G. H., Chen, L. F., and Shaner, G. 2003. Breeding for resistance to Fusarium head blight of wheat in China. Pages 296-317 in: Fusarium Head Blight of Wheat and Barley. K. J. Leonard and W. R. Bushnell, eds. The American Phytopathological Society, St. Paul, MN.

4. Bai, G. H., and Shaner, G. 1996. Variation in Fusarium graminearum and cultivar resistance to wheat scab. Plant Dis. 80:975-979.

5. Barug, D., and Kerkenaar, A. 1984. Resistance in mutagen-induced mutants of Ustilago maydis to fungicides which inhibit ergosterol biosynthesis. Pestic. Sci. 15:78-84.

6. Brandfass, C., and Karlovsky, P. 2008. Upscaled CTAB-based DNA extraction and real-time PCR assays for Fusarium culmorum and $F$. graminearum DNA in plant material with reduced sampling error. Int. J. Mol. Sci. 9:2306-2321.

7. Brent, K. J., and Hollomon, D. W. 2007. Fungicide resistance: The assessment of risk. FRAC Monogr. No. 2, 2nd ed. Fungicide Resistance Action Committee, Brussels.

8. Buchenauer, H. 1987. Mechanism of action of triazolyl fungicides and related compounds. Pages 205-232 in: Modern Selective Fungicides. H. Lyr, ed. Gustav-Fischer-Verlag, Jena, Germany.

9. Chen, Y., and Zhou, M. G. 2009. Sexual recombination of carbendazim resistance in Fusarium graminearum under field conditions. Pest. Manage. Sci. 65:398-403.

10. Cowen, L. E. 2001. Predicting the emergence of resistance to antifungal drugs. FEMS Microbiol. Lett. 204:1-7.

11. Cowen, L. E., Anderson, J. B., and Kohn, L. M. 2002. Evolution of drug resistance in Candida albicans. Annu. Rev. Microbiol. 56:139-165.

12. Cowen, L. E., Sanglard, D., Calabrese, D., Sirjusingh, C., Anderson, J. B., and Kohn, L. M. 2000. Evolution of drug resistance in experimental populations of Candida albicans. J. Bacteriol. 182:1515-1522.

13. Debieu, D., Gall, C., Gredt, M., Bach, J., Malosse, C., and Leroux, P. 1992. Ergosterol biosynthesis and its inhibition by fenpropimorph in Fusarium species. Phytochemistry 31:1223-1233.

14. Desjardins, A. E. 2006. Fusarium Mycotoxins: Chemistry, Genetics, and Biology. The American Phytopathological Society, St. Paul, MN. 
15. De Waard, M. A., Andrade, A. C., Hayashi, K., Schoonbeek, H. J., Stergiopoulos, I., and Zwiers, L. H. 2006. Impact of fungal drug transporters on fungicide sensitivity, multidrug resistance and virulence. Pest Manage. Sci. 62:195-207.

16. De Waard, M. A., Georgopoulos, S. G., Hollomon, D. W., Ishii, H., Leroux, P., Ragsdale, N. N., and Schwinn, F. J. 1993. Chemical control of plant diseases-problems and prospects. Annu. Rev. Phytopathol. 31:403-421.

17. De Waard, M. A., Groeneweg, H., and Van Nistelrooy, J. G. M. 1982. Laboratory resistance to fungicides which inhibit ergosterol biosynthesis in Penicillium italicum. Neth. J. Plant Pathol. 88:99-112.

18. De Waard, M. A., and Van Nistelrooy, J. G. M. 1988. Accumulation of SBI fungicides in wild-type and fenarimol-resistant isolates of Penicillium italicum. Pestic. Sci. 22:371-382.

19. De Waard, M. A., and Van Nistelrooy, J. G. M. 1990. Stepwise development of laboratory resistance to DMI-fungicides in Penicillium italicum. Neth. J. Plant Pathol. 96:321-329.

20. Dill-Macky, R., and Jones, R. K. 2000. The effect of previous crop residues and tillage on Fusarium head blight of wheat. Plant Dis. 84:7176 .

21. FAO. 2004. Worldwide regulations for mycotoxins in food and feed in 2003. FAO Food and Nutrition Papers No. 81. Food and Agriculture Organization of the United Nations, Rome.

22. Godet, F., and Limpert, E. 1998. Recent evolution of multiple resistance of Blumeria (Erysiphe) graminis f. sp. tritici to selected DMI and morpholine fungicides in France. Pestic. Sci. 54:244-252.

23. Goswami, R. S., and Kistler, H. C. 2005. Pathogenicity and in planta mycotoxin accumulation among members of the Fusarium graminearum species complex on wheat and rice. Phytopathology 95:1397-1404.

24. Hamamoto, H., Hasegawa, K., Nakaune, R., Lee, Y. J., Makizumi, Y., Akutsu, K., and Hibi, T. 2000. Tandem repeat of a transcriptional enhancer upstream of the sterol 14 alpha-demethylase gene (CYP51) in Penicillium digitatum. Appl. Environ. Microbiol. 66:3421-3426.

25. Joseph-Horne, T., Hollomon, D., Manning, N., and Kelly, S. L. 1996. Investigation of the sterol composition and azole resistance in field isolates of Septoria tritici. Appl. Environ. Microbiol. 62:184-190.

26. Joseph-Horne, T., Manning, N. J., Hollomon, D., and Kelly, S. L. 1995. Defective sterol $\Delta 5(6)$ desaturase as a cause of azole resistance in Ustilago maydis. FEMS Microbiol. Lett. 127:29-34.

27. Julian, A. M., Hardy, J. E., and Lucas, J. A. 1994. The induction and characterization of isolates of Pseudocercosporella herpotrichoides with altered sensitivity to the fungicide prochloraz. Pestic. Sci. 41:121-128.

28. Kalamarakis, A. E., De Waard, M. A., Ziogas, B. N., and Georgopoulos, S. G. 1991. Resistance to fenarimol in Nectria haematococca var. cucurbitae. Pestic. Biochem. Physiol. 40:212-220.

29. Klix, M. B., Verreet, J. A., and Beyer, M. 2007. Comparison of the declining triazole sensitivity of Gibberella zeae and increased sensitivity achieved by advances in triazole fungicide development. Crop Prot. 26:683-690.

30. Kuck, K. H., Scheinpflug, H., and Pontzen, R. 1995. DMI fungicides. 205-258 in: Modern Selective Fungicides. H. Lyr, ed. Gustav-FischerVerlag, Jena, Germany.

31. Leroux, P., Albertini, C., Gautier, A., Gredt, M., and Walker, A. S. 2007. Mutations in the CYP51 gene correlated with changes in sensitivity to sterol 14 alpha-demethylation inhibitors in field isolates of Mycosphaerella graminicola. Pest Manage. Sci. 63:688-698.

32. Lysoe, E., Klemsdal, S. S., Bone, K. R., Frandsen, R. J. N., Johansen, T., Thrane, U., and Giese, H. 2006. The PKS4 gene of Fusarium graminearum is essential for zearalenone production. Appl. Environ. Microbiol. 72:3924-3932.

33. Madden, L. V., Knoke, J. K., and Louie, R. 1982. Considerations for the use of multiple comparison procedures in phytopathological investigations. Phytopathology 72:1015-1017.

34. Maier, F. J., Miedaner, T., Hadeler, B., Felk, A., Salomon, S., Lemmens, M., Kassner, H., and Schafer, W. 2006. Involvement of trichothecenes in fusarioses of wheat, barley and maize evaluated by gene disruption of the trichodiene synthase (Tri5) gene in three field isolates of different chemotype and virulence. Mol. Plant Pathol. 7:449-461.

35. Mavroeidi, V. I., and Shaw, M. W. 2005. Sensitivity distributions and cross-resistance patterns of Mycosphaerella graminicola to fluquinconazole, prochloraz and azoxystrobin over a period of 9 years. Crop Prot. 24:259-266.

36. Mesterházy, Á. 2003. Control of Fusarium head blight of wheat by fungicides. Pages 363-380 in: Fusarium Head Blight of Wheat and Barley. K. J. Leonard and W. R. Bushnell, eds. The American Phytopathological Society, St. Paul, MN.

37. Mukhopadhyay, K., Prasad, T., Saini, P., Pucadyil, T. J., Chattopadhyay, A., and Prasad, R. 2004. Membrane sphingolipid-ergosterol interactions are important determinants of multidrug resistance in Candida albicans. Antimicrob. Agents Chemother. 48:1778-1787.

38. Nakaune, R., Adachi, K., Nawata, O., Tomiyama, M., Akutsu, K., and Hibi, T. 1998. A novel ATP-binding cassette transporter involved in multidrug resistance in the phytopathogenic fungus Penicillium digitatum. Appl. Environ. Microbiol. 64:3983-3988.

39. O’Donnell, K., Kistler, H. C., Tacke, B. K., and Casper, H. H. 2000. Gene genealogies reveal global phylogeographic structure and reproductive isolation among lineages of Fusarium graminearum, the fungus causing wheat scab. Proc. Natl. Acad. Sci. USA 97:7905-7910.

40. O’Donnell, K., Ward, T. J., Geiser, D. M., Kistler, H. C., and Aoki, T. 2004. Genealogical concordance between the mating type locus and seven other nuclear genes supports formal recognition of nine phylogenetically distinct species within the Fusarium graminearum clade. Fungal Genet. Biol. 41:600-623.

41. Parry, D. W., Jenkinson, P., and McLeod, L. 1995. Fusarium ear blight (scab) in small grain cereals - a review. Plant Pathol. 44:207-238.

42. Reimann, S., and Deising, H. B. 2005. Inhibition of efflux transportermediated fungicide resistance in Pyrenophora tritici-repentis by a derivative of 4 '-hydroxyflavone and enhancement of fungicide activity. Appl. Environ. Microbiol. 71:3269-3275.

43. Rotter, B. A., Prelusky, D. B., and Pestka, J. J. 1996. Toxicology of deoxynivalenol (vomitoxin). J. Toxicol. Environ. Health 48:1-34.

44. Schnabel, G., and Jones, A. L. 2001. The 14 alpha-demethylase (CYP51A1) gene is overexpressed in Venturia inaequalis strains resistant to myclobutanil. Phytopathology 91:102-110.

45. Schoustra, S. E., Debets, A. J. M., Slakhorst, M., and Hoekstra, R. F. 2006. Reducing the cost of resistance; experimental evolution in the filamentous fungus Aspergillus nidulans. J. Evol. Biol. 19:1115-1127.

46. Selmecki, A., Gerami-Nejad, M., Paulson, C., Forche, A., and Berman, J. 2008. An isochromosome confers drug resistance in vivo by amplification of two genes, ERG11 and TAC1. Mol. Microbiol. 68:624-641.

47. Serfling, A., Wohlrab, J., and Deising, H. B. 2007. Treatment of a clinically relevant plant-pathogenic fungus with an agricultural azole causes cross-resistance to medical azoles and potentiates caspofungin efficacy. Antimicrob. Agents Chemother. 51:3672-3676.

48. Stehmann, C., and De Waard, M. A. 1996. Sensitivity of populations of Botrytis cinerea to triazoles, benomyl and vinclozolin. Eur. J. Plant Pathol. 102:171-180.

49. Wellmann, H., and Schauz, K. 1992. DMI-Resistance in Ustilago maydis. I. Characterization and genetic analysis of triadimefon-resistant laboratory mutants. Pestic. Biochem. Physiol. 43:171-181.

50. Wellmann, H., Schauz, K., and Tiemann, R. 1996. Resistance to sterol demethylation inhibitors in Ustilago maydis. III. Cross-resistance patterns and sterol analyses. Pestic. Sci. 48:239-246.

51. Wyand, R. A., and Brown, J. K. M. 2005. Sequence variation in the CYP51 gene of Blumeria graminis associated with resistance to sterol demethylase inhibiting fungicides. Fungal Genet. Biol. 42:726-735.

52. Yin, Y., Liu, X., Li, B., and Ma, Z. 2009. Characterization of sterol demethylation inhibitor-resistant isolates of Fusarium asiaticum and F. graminearum collected from wheat in China. Phytopathology 99:487-497.

53. Zinedine, A., Soriano, J. M., Molto, J. C., and Manes, J. 2007. Review on the toxicity, occurrence, metabolism, detoxification, regulations and intake of zearalenone: An oestrogenic mycotoxin. Food Chem. Toxicol. 45:1-18. 